elderly ${ }^{6}$ and may be the innocent victims of the lust for speed of some drivers.

Those who make policy must understand that any decision to relax the enforcement of laws on speeding is to condemn some of our citizens to death. ${ }^{7}$ The present publicity is about speeding on motorways, but a speed of above 90 miles/hour (144 km/hour) on motorways often converts to 50 miles/hour $(80 \mathrm{~km} /$ hour$)$ or above on urban thoroughfares, which include shopping streets, and to $40 \mathrm{miles} / \mathrm{hour}$ ( $64 \mathrm{~km} /$ hour) or above on residential streets, which include children's play areas. Though no speed is safe, a safer speed is a lower speed. Legislation to control speed is in the interest of both individual people and the community to reduce deaths, injuries, and damage to property and the costs of these losses. Enforcing speed limits is not particularly difficult: the technology, capable of photographing a vehicle (even in fog) and superimposing its speed, date, and location, has existed for over a decade. ${ }^{1}$

ROBERT WEST

Senior Lecturer,

Department of Epidemiology and Community Medicine,

University of Wales College of Medicine,

Cardiff CF4 4XN

1 Department of Transport. Road accidents for years 1972-86. London: HMSO, 1973-87.

2 Office of Population Censuses and Surveys. Mortality statistics in England and Wales 1974-85. London: HMSO, 1975-87.

3 Road research laboratory. Research on road safety. London: HMSO, 1963.

4 Whitlock FA. Death on the road: study in social violence. London: Tavistock, 1971.

5 Harvey AC, Durbin J. Effect of seat belt legislation on British road casualties. Fournal of the Royal Statistical Society 1986;149:187-210.

National Consumer Council. What is wrong with walking? London: HMSO, 1987.

7 Foege WH. Highway violence and public policy. $N$ Engl f Med 1986;316:1407-8.

\title{
The longitudinal study and the social distribution of cancer
}

\author{
The study will produce vital information
}

Prospective studies in which many subjects are followed over many years to determine their pattern of mortality and incidence of cancer are major undertakings. The Office of Population Censuses and Surveys helps health workers enormously by identifying relevant events among subjects in such studies through the National Health Service central register. In 1971 the office started a prospective study, the longitudinal study, of about $1 \%$ of the population of the 1971 census-over 570000 people. This made it the largest prospective study in Britain and comparable in size with the large studies of mortality by the American Cancer Society (about one million people) and the National Institutes of Health (about 250000 military veterans). The relation of the demographic and social factors covered by the census to disease may thus be studied in a representative sample of the whole population.

The longitudinal study is an ambitious study that adds an extra dimension to the statistical information provided by the Registrar General. Only the Office of Population Censuses and Surveys could have carried out the study as it is guardian of the census and could perform the whole enterprise inhouse, thereby preserving the confidentiality of the census. The latest publication ${ }^{1}$ from the study is the first on the incidence of cancer, and it complements an earlier report on mortality. ${ }^{2}$ It contains a wealth of detail not only on social factors but also on marital state, parity, and age at first birth, with more than 100 tables as well as 25 figures.

The importance of socioeconomic factors in the causation of cancer is well known. Little is known, however, about how socioeconomic factors increase cancer, apart from smoking, which explains the higher incidence of lung cancer in those who are poorer. Much of the information on socioeconomic factors and cancer has come from cross sectional surveys in which the social and occupational details are collected after the event, which obviously allows scope for bias. Indeed, the quality of the occupational data on death certificates for many retired people is such that the Registrar General restricts the main analyses on this subject to people aged under 65 . The longitudinal study, however, allows mortality and the incidence of cancer to be studied in relation to social factors even when the relevant events occur well past the usual retirement age.
The longitudinal study is probably also unique in using five variables from the census that are relevant to the social distribution of cancer-namely, housing tenure, access to household amenities, access to cars, educational qualifications, and social class. These are, of course, interrelated, but they must all be examined if every attempt is to be made to understand the nature of social influences on the causes of cancer. The present study confirms the validity of the Registrar General's broad social class groupings. It finds for example, that whichever of the five measures is used the incidences of cancers of the stomach, lung, and cervix are highest in those in the lowest socioeconomic groups, whereas the reverse (although less pronounced) is the case for cancers of the breast and ovary.

The report also indicates something of what the longitudinal study could produce in the future. The accuracy and reliability of the national scheme of cancer registration is becoming more important with the increasing interest, among both the public and scientists, in cancer in small areas, such as near Sellafield and Dounreay. The longitudinal study has the potential to validate certain aspects of this scheme. Furthermore, it may examine not only cancer survival in relation to social and other factors but also the prevalence of cancer.

The study deals, however, only with the time from 1971 to 1975 , presumably because this was the only quinquennium for which cancer registrations for the whole country were regarded as fairly complete when the analysis was started. Mention is made that a large number of recent registrations have now been linked to the cohort and are awaiting analysis. We must hope that resources may be found to continue to exploit this study, which is perhaps the largest cohort study of the incidence of cancer in the world. It promises to be a fruitful source of information for years to come.

Director,

L J KINLEN

Cancer Research Campaign,

Cancer Epidemiology Unit,

University of Edinburgh,

Edinburgh EH8 9JZ

\footnotetext{
1 Leon DA. Longitudinal study: social distribution of cancer. London: HMSO, 1988. (Series LS No 3

OPCS.)
Fox AJ, Goldblatt PO. Longitudinal study: sociodemographic mortality differentials. London: HMSO, 1982. (Series LS No 1 OPCS.)
} 